\title{
ESTRATÉGIAS DE REPRODUÇÃO SOCIAL CAMPONESA: O PODER DE RESISTÊNCIA DA JUVENTUDE RURAL, VALE DO JARUI, TOCANTINS
}

Adelma Ferreira Souza

Sonia Maria P. Pereira Bergamasco ${ }^{2}$

Eonilson Antônio Lima

Resumo: O presente trabalho objetivo apresentar as condições para a reprodução social camponesa entre as novas gerações no vale do Juari, região noroeste estado do Tocantins. Trata-se, portanto, de compreender porque, diferente de outros estudos sobre a reprodução camponesa e sucessão rural, as novas gerações, inclusive as mulheres, querem ficar no campo. Entende-se que a política de reforma agrária foi vetor para assegurar as novas gerações de camponeses o retorno e acesso à terra. Observa-se que "escolha" dos jovens (homens e mulheres) de continuar nos assentamentos rurais na região do vale não está orientada só pelas internalizações subjetivas de valores apreendidos no processo de socialização, isto é, pelo habitus como também, pelas condições objetivas de reprodução social da vida local. Neste sentido, fez-se uso da História de vida para apreender as trajetórias sociais e os arranjos fundiários, econômicos e sociais que as famílias vêm engendrando que possibilita os filhos (as) e netos (as) ver o campo como "um negócio possível", garantindo assim as práticas de reprodução da produção familiar e sucessão da condição camponesa em assentamentos rurais na região.

Palavras-chaves: Juventude Rural; Reprodução Social; Assentamentos Rurais; Sucessão Rural.

\footnotetext{
${ }^{1}$ Graduação em Ciencias Sociais (FFBS), Doutorado em Ciências Sociais (Unicamp), Docente (IFTO) Antropóloga (INCRA).E-mail: adelma.souza@ifto.edu.br

${ }^{2}$ Professora do Programa de Pós graduação em Ciencias Sociais (Unicamp). Bolsista de Produtividade em Pesquisa pelo CNPq e Bolsista PVNS - CAPES Professor Visitante Nacional Sênior - 2013-2017 do Programa de Pós Graduação em Agroecologia e Desenvolvimento Rural da Universidade Federal de São Carlos - Campus Araras. ${ }^{3}$ Graduação em História (UNITINS), Mestrando em História (UFG), Docente (SEDUC/Tocantins) E-mail: eonilsonlima@gmail.com
} 
Abstract: This present work presents the conditions for peasant social reproduction among the new generations in the Juari valley, northwest region of Tocantins. It is therefore necessary to understand why, unlike other studies on peasant reproduction and rural succession, new generations, including women, want to stay in the field. It is understood that the policy of agrarian reform was a vector to ensure the new generations of peasants the return and access to land. It is observed that the "choice" of young people (men and women) to continue in the rural settlements in the valley region is not oriented only by the subjective internalizations of values seized in the socialization process, that is, by the habitus as well, by the objective conditions of Social reproduction of local life. In this sense, life history was used to understand the social trajectories and the social, economic and social arrangements that families have been generating that makes it possible for the children and grandchildren to see the field as "a possible business", Thus guaranteeing the practices of reproduction of family production and succession of the peasant condition in rural settlements in the region.

Keywords: Rural Youth; Social Reproduction; Rural Settlements; Rural Succession.

\section{Introdução}

Bourdieu, nos anos 60, e Champagne, na década de 80 , estudaram os processos de crise e reprodução social do campesinato na França gerados pela "dinâmica de urbanização" ou pelo "alagamento social do espaço". Desde então, a migração camponesa para meio urbano se fez presente em estudos sobre campesinato, juventude e mundo rural. Em que pesem as particularidades históricas, no Brasil a conjuntura não foi diferente. A literatura que tangencia a "juventude rural" como temática aponta o "tema problema”: ficar/sair do campo, migração, circulação (CASTRO, 2013). Sair ou ficar no campo é um dilema que permeia o universo do jovem especialmente as mulheres, tidas, em tais estudos, como mais propensas à emigração - e se relaciona com "arranjos" para realizar projetos de vida e a autonomia econômica, individual e do grupo geracional.

Juventude rural não é categoria homogênea. É entendida conforme os contextos econômicos, políticos, sociais e as realidades culturais, como se lê em Abramovay (1998), Durston (1996), Brumer, Souza e Zorzi (2002),
Brumer (2007), Wanderley (2003), Weishemeier (2004), Stropasolas (2006), Carneiro e Castro (2007), Castro (2013); Wanderley (2013a). Não se pode definir "jovens" apenas pela idade cronológica ou pelo ciclo de vida. "[...] são arbitrários culturais e regras socialmente construídas que determinam quando, como e por meio de quais rituais as sociedades reconhecem as passagens entre estas fases da vida" (NOVAES, 2004, p. 1). Nas últimas décadas, os estudos sobre a juventude rural abordaram a heterogeneidade das pessoas incluídas nessa categoria. Há diversidade não apenas regional, mas também cultural, social e econômica entre os setores que compõem a juventude rural brasileira.

Embora seja diversa a concepção, em geral a categoria juventude é definida por pesquisadores e estudiosos como fase de transição gradual para o papel de adulto e a posição hierárquica de subalternidade à família. Do ponto de vista dos deveres e das obrigações, é uma fase de transição, aprendizado e preparação para o futuro, para a sucessão dos pais via transmissão de bens e terra ou para a realização de projetos de vida. Castro (2013), em seu esforço para analisar a construção e reordenação da categoria "juventude rural", diz que está envolve questões objetivas — renda, trabalho, acesso à escola - e subjetivas - autoridade paterna, divisão sexual do trabalho, disputa por poder e privilégios em contextos múltiplos, conforme a posição dos agentes no espaço de sociabilidade onde atuam.

Eis, então, a perspectiva deste artigo abordar a questão dos jovens nos assentamentos rurais pelo viés geracional para compreender, no campo familiar, o "jogo de lutas" (BOURDIEU, 2013) e as relações de força física, econômica e simbólica - que se operam nos processos geracionais de reprodução social e cultural do campesinato. A proposta é analisar as aspirações das gerações descendentes - filhos e netos de assentados; seus projetos de vida, bem como, os mecanismos sociais e simbólicos que vem orientando a continuidade do modo de vida camponês no Vale do Juari entre as novas gerações. Espaço social marcado por processos de luta pelo direito ao acesso à terra que atravessaram três gerações de famílias.

A estratégia metodológica foi obter relatos orais sobre as trajetórias das seis famílias a partir da primeira geração que conquistou a terra e foi incluída nos assentamentos. Seguindo esse raciocínio, o uso da "história de vida" foi importante para evocar a memória social dos filhos e netos sobre suas trajetórias sociais, a relações familiares e os processos de luta pela terra vivenciados. $\mathrm{O}$ intuito era apreender as subjetividades ocultas na 
memória dos jovens e suas famílias. Nessa perspectiva, a "história de vida" foi utilizada como técnica e como método, pois "[...] apenas a fonte oral permite-nos desafiar essa subjetividade: descolar as camadas da memória, cavar fundo em suas sombras, na expectativa de atingir a verdade oculta" (THOMPSON, 2002, p. 197).

A pesquisa de campo foi realizada na região do Vale do Juari, território que integra um mosaico com 7 assentamentos rurais próximos, onde estão assentadas 556 famílias em perímetros de 36.083.1367 hectares, sendo que, nos municípios que circundam este território, foram criados outros 20 assentamentos rurais, com mais 1.496 famílias assentadas (INCRA, 2016). Os municípios de Pequizeiro, Couto de Magalhães, Juarina e Bernardo Sayão, que são eminentemente rurais. A população dos quatros municípios soma-se 16.750 habitantes: 7.494 moram em áreas urbanas, 9.256 residem em áreas rurais - como mostra o Censo de 2010. Estes assentamentos são resultados das persistentes lutas camponesas pelo acesso à terra, engendradas a partir da década 1980, com apoio de diversos agentes- Igreja Católica, Sindicato dos Trabalhadores Rurais, Comissão Pastoral da Terra, alcançando as primeiras décadas dos anos 2000 .

A pesquisa envolveu assentados de três gerações, ao todo, foram entrevistados 62 pessoas de faixas etárias diferenciadas: 10 pais e mães na faixa etária 52-71 anos; 18 jovens, segunda e terceira geração, com idades 18-29 anos e 36 adultos 30-50 anos envolvendo os cônjuges. Estas famílias possuem lotes em 6 assentamentos rurais localizados na região do Vale do Juari, na região do Médio Araguaia, fronteira com sul do Pará.

\section{Além do ir e do ficar: mecanismos de reprodução geracional camponesa}

Antes de adentrar nos mecanismos de reprodução da condição camponesa no vale do Juari, convém apresentar as condições que levaram jovenshomens e mulheres- a aspirações subjetivas (BOURDIEU, 2002b;1962) de permanecer ou retorna ao campo. Os (as) jovens e adultos, estudados nesta pesquisa, são filhos (as) e/ou netos (as) de camponeses posseiros que sofreram com as transformações socioeconômicas, políticas e culturais ocasionadas pela expansão territorial do capital na Amazônia, situação análoga em outras regiões, expropriaram as suas terras camponesas na década de 60 e modificaram o modo de (re) produção material e espiritual dos povos do campo - diria Ianni (2002).

As famílias eram camponeses-garimpeiro-posseiros oriundos do Nordeste, sobretudo do Piauí e do Maranhão, que vieram para norte goiano ainda no final dos anos 30 em busca de melhoria para "tocar a vida" na atividade garimpeira e no plantio de roças em terras devolutas. Na primeira metade do século XX, as terras do antigo norte de Goiás (hoje Tocantins) eram ainda "liberadas" possibilitando às famílias camponesas se "situarem" e assegurar suas condições de existência social.

A transmissão de conhecimentos e processos de socialização estava circunscrita à vida local, mediada por relações cotidianas e práticas de reciprocidade entre moradores. Nesse microcosmo social de isolamento de influências externas, a lógica familiar de trabalhar na agricultura ressurgia quase automaticamente entre os filhos, apreendida nos processos de socialização. A aprendizagem das crianças, como iniciação nas habilitações dos adultos, começava desde cedo. Meninos e meninas já auxiliavam os pais nas atividades produtivas e de consumo. Aprendiam técnicas produtivas em atividades domésticas para garantir a reprodução material e social da família. Essa forma de aprender se abre à compreensão à luz de Thompson (1998, p. 18), para quem ocorre a transmissão não só de técnicas particulares, mas também "[...] de experiências sociais ou de sabedoria comum da coletividade" - a transmissão do habitus camponês entre gerações, diriam Bourdieu (1962) e Champagne (1986).

As famílias ocupantes do Vale do Juari sofreu na década 1960 expropriação das suas terras com a expansão territorial do capital, materializada nas fazendas agropecuárias. O desapossamento de suas terras e a instalação de condições econômicas alheias ao seu modo de vida impeliram os camponeses a engendrar diferentes arranjos conforme os capitais (BOURDIEU, 2013) que possuíam ou movimentaram para viabilizar as bases materiais de produção e reprodução da sua existência social. Com o estabelecimento da lógica capitalista na região, eles foram transformados em "moradores de favor" (MOURA, 1988b). Passaram a se sujeitar aos domínios dos latifundiários agropecuaristas como agregados, meeiros, arrendatários, peões e vaqueiros.

Por quase duas décadas estes conheceram um processo de desenraizamento profundo. Eliminados das possibilidades urbanas de arrumar trabalho formal, viveram em condições de miséria e exclusão nas periferias das pequenas cidades da região. Mas, o "espírito de família" (BOURDIEU, 2013) 
foi acionado entre os membros para, no esforço coletivo, garantir a sua reprodução, driblar a proletarização e assegurar "os mínimos vitais. Todos os membros da família se degradaram no roçado, nas ruas na condição de pedinte (no caso dos filhos e filhas menores), nos serviços de empregada doméstica e em subempregos urbanos. Mas, aí reside o poder da resistência das famílias, segundo Bourdieu (1979), é a necessidade tornada virtude para evitar a diluição da unidade familiar.

Entretanto em meados da década de 80 o território do vale do Juari começa a reconfigurar-se. As transformações políticas e sociais que ocorreram no Brasil em meados dos anos 80 — após o fim o governo militar - e o movimento de redemocratização impulsionado por organizações sociais e partidos políticos de bases populares, alterando o espaço agrário da região do médio Araguaia. Houve uma mudança profunda na estrutura fundiária da região desencadeando um processo de recamponeização (Almeida, 2006). O espaço social marcado por latifúndios pecuaristas se redefiniu em função das lutas campesinas para garantir a base material de produção e a reprodução sociocultural do modo de vida camponês, constituindo na territorialização dos assentamentos rurais. Os processos de luta pela terra engendraram às gerações descendentes disposições no sentido bourdesiano-, para lutar pela terra e garantir a reprodução da condição camponesa entre as novas gerações.

\section{O sentido da terra para os jovens: assentamento como lugar de vida}

Apreendendo as trajetórias de jovens e adultos de hoje que eram crianças ou jovens à época das primeiras ocupações de terras no vale do Jauri, que vivenciaram a situação de proletarização das famílias na cidade após a expropriação das terras, e que trazem na memória as marcas da escassez de alimento - o "desespero da fome" — , a conquista da terra representou a reconstituição da condição camponesa e a rearticulação o lugar de morada com lugar de trabalho. O assentamento seria um espaço onde se constroem relações identitárias fundadas nos laços de parentesco e vizinhança que não só envolvem a vida cotidiana e a inserção na sociedade, mas também determinam os ciclos da vida familiar e as manifestações culturais e religiosas (WANDERELY, 2000a).

As trajetórias geracionais se sobrepõem e vêm produzindo mudanças profundas nesse espaço agrário ao permitir às gerações descendentes internalizar probabilidades objetivas (BOURDIEU, 1962) de permanecer no campo. Observa-se uma forte identificação das novas gerações com a família, a terra e com a vizinhança nos assentamentos rurais. A perspectiva do assentamento como o "lugar de vida" é infundida por uma dimensão temporal que intermedeia o passado das tradições familiares, orientando as práticas e as estratégias do presente centradas na educação, no trabalho e nos espaços de sociabilidades; inspiram alternativas possíveis às gerações futuras para reprodução de seu modo de vida (WANDERLEY, 2013a).

O lote/chácara/sitio no assentamento rural propiciou o reencontro da terra com a família — a unificação do espaço da "casa" com a "roça" permitiu ao "pai de família" sair da sujeição a terceiros e pôr fim à vida errante de "peão da juquira", à situação residual de meeiro ou de vaqueiro. O significado da terra e o fortalecimento da unidade familiar são registrados na fala de Marilene Marujada (33), assentada no Vale do Barreira. Quando perguntada sobre a conquista do lote e a chegada ao assentamento, disse que "[...] era uma maior felicidade naquele tempo, da gente ter um pedaço de terra para plantar. [...] Meu pai ficou muito feliz em saber que não era mais preciso trabalhar pros outros, que tinha um pedaço de terra para trabalhar e sustentar a gente" (2015, entrevista).

No vale do Juari, a terra vai além do capital econômico, pois agrega o peso simbólico das lutas travadas pelas famílias camponesas contra a vida de sujeição aos domínios econômico, político e jurídico dos grandes proprietários para garantir o patrimônio familiar.

\section{Sucessão nos assentamentos: arranjos familiares e os destinos sociais dos (as) jovens no vale do Juari}

A experiência de nascer ou crescer em assentamento rural permitiu aos jovens desenvolver o gosto pelo campo e orientou o desejo nestes de ser camponês. Para filhos e filhas, netos e netas de camponeses, porém, a "escolha" de continuar nos assentamentos na região do vale não está orientada só pelas internalizações subjetivas de valores apreendidos no processo de socialização, mas também pelas condições objetivas de reprodução social da vida local. Ela alinha as oportunidades de crescimento profissional no acesso ao trabalho, na escolarização nas cidades da região e na conquista do patrimônio fundiário como projeto de vida e de geração de renda.

Este estudo constatou que a região em torno do vale tem particularidades que afetam a decisão de "ficar ou sair" do campo em meio a novas gerações de assentados. Por um lado, há pujança na vida rural decorrente do número 
de assentamentos rurais (27), os quais agregam uma população de 6,2 mil residentes, superior à população urbana de municípios circundantes. Há uma circulação constante entre campo e cidade. Por outro lado, a capacidade incipiente do tecido urbano (CARRIÉRE, s. d.) de integrar a força de trabalho camponesa excedente - ante a ausência de desenvolvimento industrial e escassez de serviços urbanos ou espaços de lazer nesses municípios desestimula a emigração dos jovens.

Dados secundários sobre os municípios permitem traçar a configuração do espaço social local e ajudam a compreender a decisão dos jovens de continuar a experiência camponesa. A economia dos quatro municípios que circundam o vale do Juari está baseada na agropecuária (quase $25 \%$ ), na administração e nos serviços públicos municipais (quase 51\%) (IBGE, 2010). As cidades têm população inferior a dez mil habitantes. Faltam instituições como universidades públicas - as que existem, são instituições privadas cujos custos mensais são incompatíveis com a renda familiar. Daí o desânimo dos (as) jovens quanto a continuar a formação escolar no ensino superior. Em 2014, foi criado um campus do Instituto Técnico Federal de Tocantins em Colinas. Mas a oferta do primeiro curso superior - em Agronomia - foi programada para acontecer em 2017.

No geral, ao terminar o ensino médio no município-sede, os jovens se veem ante um dilema: ou casar-se e buscar alternativas para seguir a profissão do pai, ou migrar à procura de emprego urbano para continuar a formação educacional. Nesse contexto, nem sempre é possível alinhar os sonhos ou as expectativas de formação profissional na realidade concreta vivenciadas pelos (as) jovens. Essa impossibilidade tende a definir a continuidade de estratégias para permanecer no campo. Entretanto, mesmo com empecilhos, os/as jovens, seguem com o sonho de concluir o ensino superior. A escolha da profissão está ligada à área da educação, ciências agrárias, social ou saúde. Segundo relataram, poderiam conseguir empregos e continuar na terra como professor de Educação Física, assistente social, enfermeiro (a) e agrônomo.

Se os/as jovens estão perdendo o encanto pela vida nas cidades da região, também estão valorizando as experiências bem-sucedidas de pais e avós após a conquista da terra e o desenvolvimento de atividades agropecuárias com a produção do leite. Estas materializam a melhoria de vida da família - em forma de renda mensal, crédito-habitação, programa Luz para Todos, acesso a créditos do PRONAF e de políticas sociais para meio rural (políticas de infraestrutura e melhoria da educação e saúde no assentamento), acesso a carros, motos e eletrodomésticos (aparelhos de tevê, microondas e taque de lavar roupa, liquidificador, fogão a gás etc.); acesso a formas de comunicação como telefone celular e internet em alguns pontos dos assentamentos.

Tais reconhecimentos e expectativas, que podem ser depreendidos dos extratos de relatos a seguir - inclusive de filhos (as) que não moram no assentamento - , orientam as decisões dos jovens de permanecer ou retornar no campo:

Pra mim tá melhor. Antes a gente não tinha acesso a nada. Hoje, na zona rural, tem energia, você pode usar a televisão, você pode ter uma geladeira, você pode comer uma fruta gelada, pode ter uma carne gelada que não vai perder. [...] Você vai pra roça, você tem tudo que tem na cidade; só não tem internet, mas o que tem aqui [Couto Magalhães] lá tem melhor ainda. Se você tiver uma renda pra se manter lá, 'tá muito melhor que na cidade (Edson SOARES, 2015, entrevista)

Uma questão estrutural e estruturante na reprodução geracional camponesa é o acesso à terra aos herdeiros para que possam garantir a continuidade do ciclo biológico após a constituição de suas famílias. Os mecanismos práticos para suprir a demanda por terra e continuar a exploração econômica dos assentamentos incluem uma negociação tácita no interior das famílias que vem sendo arranjada para dar segurança material a todos os filhos com justiça e equidade. Como locais de produção e circulação de renda, de sentimentos, de ligações afetivas, pessoais, de obrigações familiares mútuas e interesses econômicos entre os envolvidos (BESSIÉRE, 2010), os lotes/chácaras/sítios forçam as famílias a buscar alternativas para "agasalhar" os filhos ante a limitação do patrimônio familiar e as regras jurídicas com a terra.

Seguindo a linha de análise das práticas concretas engendradas pelas famílias para assegurar a prole, a pesquisa mostrou que a transmissão do patrimônio não é discutida no interior das famílias assentadas; porém, o confronto de pontos de vista levantados separadamente nas entrevistas quanto a quem herdaria o lote - pais, filhos e filhas - aponta convergência de opinião entre os membros sobre o possível herdeiro (a): são indicados os/as filhos (as) que moram com os pais, trabalham com a família e têm interesse em permanecer no lote, mas ainda não têm terras; inclusive filhos (as) que não moram no assentamento, mas querem voltar ao campo.

Das seis famílias em foco neste estudo, houve duas indicações de filhas com herdeiras do patrimônio familiar; uma delas até não mora no 
assentamento, mas frequenta os lotes dos pais. Observa-se que há uma questão moral dos pais em resguardar os filhos ainda em vida, como expõe Sr. Manoel (56) e dona Zuleide (53), o plano é continuar no assentamento e "agasalhar" todos os/as filhos (as) e deixar o lote de herança para a filha Márcia, que mora em Colinas e trabalha de manicure, assegurando assim, também os netos. Pretensão que é compartilhada por outros pais como Sr. Francisco Reis (71), que explica porque o lote onde mora ficará para filha Beatriz já tem um filho Tiago (6).

Só tem ela [Beatriz] que não tirou o lote, mas esse aqui, já falei pros outros filhos tudinho: “Aqui não tem herança pra vocês, não!”. Eu dei um para cada um. Esse aqui é pra quem tá dentro de casa. Esse aqui é dela, do menino dela, porque ela não vai trabalhar, e do outro neto que eu crio (2015, entrevista).

Pode-se compreender que a herança nos assentamentos ainda é discurso, uma promessa para filhos (as) indicados (as) a herdeiros(as). Afinal, os pais continuam em atividade, trabalhando e administrando o lote, mesmo em situações em que já estão aposentados. Como nos casos estudados por Sivestro el al. (2001), Stropasolas (2006) e Bessiére (2010), a aposentadoria rural permitiu aos pais ficar no campo e retardar o processo de transmissão da administração do patrimônio familiar. Por ser a transmissão um acordo tácito intrafamiliar, nota-se que a intenção é transmitir a gestão do lote ao herdeiro ou à herdeira só quando os genitores não puderem mais trabalhar ou após sua morte.

A expectativa dos pais é que no do filho apontado a herdeiro aja como "futuro proprietário", assuma a responsabilidade pela exploração agrícola do lote; mas nem sempre veem os jovens como "homem de honra" (BOURDIEU, 1962), cuja a preocupação deve ser a proteção dos interesses do núcleo familiar e o patrimônio da família - conquistado com sacrifício. Caso como Elder (31) que relata se sente impotente ante o autoritarismo do pai, daí sua falta de vontade de morar no lote. Diz ter dificuldades para se relacionar com pai: "Eu vou ficar em um lugar onde não me sinto dentro da própria casa? [Onde] quem dá as coordenadas de tudo é ele? Tudo é ele que manda. (2015, entrevista).

Há tensão entre pai e possível herdeiro em torno da expectativa de transferir o controle da propriedade está presente nas famílias. Os relatos de Elder (31) e Luiz Carlos expressam a luta dos jovens para encontrar seu lugar. Luiz Carlos expos que pensou em se mudar para cidade a fim de conseguir trabalho e garantir renda mensal. Sente-se envergonhado por depender dos pais financeiramente. Em suas palavras

Queria arrumar um serviço pra poder, todo mês, ter meu dinheiro pra não ficar dependendo dos outros. Na hora que quer dinheiro, tem que depender do pai da mãe. Na idade que a gente tá, fico com vergonha de depender dos outros, os de casa não fala, mas os de fora falam (2015, entrevista).

Conforme analisa Bessiére (2010, p. 135), “[...] o que está em jogo é o seu acesso à autonomia e independência da geração anterior". Autonomia se refere ao domínio do mundo em que vive. Independência está relacionada com a autosufiência, com não depender de outros economicamente .

Todavia, ocorre um processo de transição: os pais vêm democratizando as decisões, garantindo aos filhos mais autonomia financeira na propriedade familiar com transferência de parte da renda obtida com a venda do leite; ajudando na compra de carros e motos para que possa ter mais autonomia de deslocamento, acompanhá-los na cidade a fim de fazer as compras, resolver transações bancárias e negociar preço do leite diretamente nos laticínios da região. Como entre as famílias estudadas, a predominância dos filhos é do sexo masculino, esta autonomia está restrita aos filhos homens, pois há apenas uma filha mulher que ainda está morando no lote do pai [Beatriz]. Porém as jovens filhas casadas têm autonomia junto aos seus maridos na propriedade, também participam das discussões sobre o planejamento do lote, dirigem motocicletas, se deslocam sozinhas para cidade-sede do município trabalhar, comercializar produtos, resolver questões relacionadas ao lote.

Nos assentamentos do vale do Juari, o sistema da unigenitura está sendo possível graças a arranjos que os membros das famílias têm, de alguma forma, engendrado para resolver problemas de equidade em meio à prole. Os mecanismos nem sempre envolvem questões monetárias; antes, supõem estratégias variadas para compensar os/as herdeiros (as), seja com a garantia de patrimônio fundiário ou a acumulação de capitais como a educação para "agasalhar" as novas gerações.

Ante a extensão limitada das terras para um número elevado de filhos (as) (herdeiros) na família da primeira geração, além dos poucos recursos econômicos das famílias, a emigração dos/as jovens se apresenta como tendência quase "natural". A motivação inclui a aspiração a vivenciar 
experiências e a expectativa de trabalhar com salário fixo, em geral em ocupação urbana, ou o sonho de continuar a formação escolar. Além disso, segundo Castro (2013), "sair de casa" pode significar o rompimento com o controle paterno e a dependência econômica. No entanto, nem sempre é uma saída definitiva. Pode ser uma estratégia para permanecer no campo e, portanto, reproduzir sua condição camponesa, como foi discutido por Garcia Júnior (1989), Menezes (1985; 2002), Woortmann (2009), Silva (1992), Menezes e Silva (2009) e Carneiro e Castro (2007). Muitas vezes - analisa Wanderley (2007) - , a saída não representa rompimento com laços familiares nem com o assentamento. É um novo contorno social em que o jovem refaz sua trajetória em movimentos múltiplos e com estratégias econômicas diferentes. A família e o assentamento são referências para ele.

Caso dos filhos Leonardo (34) e Lucas (36) filhos de Raimundo e Manuela Marujada que em 2002 foram para Irlanda par trabalhar na construção civil entre os anos de 2002 a 2006. Entre idas e vindas ficaram quatro anos trabalhando para adquirir um patrimônio para reinvestir e recuperar a sua condição de camponês. Em 2006, voltaram ao Brasil. Lucas se casou com missionária irlandesa e regressou para Dublin. Leonardo (34) se casou com uma moça de Colinas do Tocantins em 2007 e comprou "direito de lote" no assentamento Progresso, onde mora. Agregando a vida de camponês aos conhecimentos adquiridos na cidade, montou uma empresa de construções com o vizinho. Prestam serviços de construção e reformas de casas nos assentamentos rurais da região.

À medida que se expandiram os núcleos familiares com a constituição de novas unidades domésticas, continuou a "sede de terra". Orientados por um dever moral "agasalhar" a prole, os pais adotaram estratégias como investir em gado. Seria uma forma de acumular economias para auxiliar os/as filhos(as) na aquisição da própria terra ou ajudá-los por outras vias na conquista do lote.

Mas, ante ao pouco capital econômico, a compra de lotes ou "direito de lote" para mais de um filho morar e administrar foi uma prática recorrente entre as famílias. Entretanto, o gerenciamento plurigeracional dos lotes adquiridos em sociedade para irmãos foi uma experiência não muito bemsucedida no vale do Juari, devido as tensões entre irmãos e cunhadas, quanto a gestão do lote e a divisão das atividades domésticas. Norteadas por relações familiares situadas no "coração das trajetórias sociais" (BESSIÉRE, 2010), as famílias vêm fazendo um sacrifício coletivo para auxiliar os descendentes a conquistar terra, resguardando as novas gerações a possibilidade de permanecer no campo. A criação do gado, além de reserva/poupança, é vista pelas famílias do vale do Juari como espécie de dote de pais ou avós para as jovens no momento do casamento.

Famílias com prole mais numerosa não têm capital disponível para garantir a todos a terra por meio da compra do "direito de lote". Ante aspirações de filhos/as e netos/ de, na maioria das vezes, continuar no campo e o desejo dos pais ou avós de tê-los por perto, ocupar latifúndios improdutivos é o arranjo que persiste há três gerações familiares e tem garantido aos mais novos a reprodução sociocultural da condição de camponês no vale do Juari.

Com efeito, a partir da segunda metade dos anos 2000, ocorrem novas ocupações de latifúndios improdutivos no vale. Em 2007, surge novas ocupações a fim de suprir a demanda de famílias a terra para atender as novas unidades domesticas constituídas, articuladas por representantes políticos do Partido dos Trabalhadores a nível municipal e estadual para mediar as negociações com fazendeiro para criar o assentamento. Os/as jovens da família marujada- Marilene Marujada e o marido e o Marcos primo Marcos Marujada e a família foram os primeiros ocupantes da fazenda, hoje assentamento Vale do Barreira. Logo a notícia se espalhou, e outras 30 famílias acamparam na sede a fim de esperar a desapropriação. Quando perguntada sobre o que a motivou a ir para o assentamento, ela respondeu: "Eu, sempre meu maior sonho é ter uma terra para trabalhar... criar os filhos. Foi um sonho realizado, tenho vontade de trabalhar na roça".

Em 2009 houve outra ocupação de terra em fazenda contígua ao assentamento Progresso. Vinte pessoas acamparam nela. A maioria era filho de assentados. Como em ocupações precedentes, não havia organização de movimentos sociais rurais. "[...] foi mesmo vivendo e aprendendo" — como relata Luiz Pereira (24). Os jovens estavam norteados pela experiência das gerações anteriores sobre os processos de ocupação. Luiz Pereira, que já havia vivido com avô em acampamento do Movimento dos Trabalhadores Rurais Sem Terra (MST) e outros jovens filhos (as) e netos (as) das primeiras famílias a ocuparem terras no vale do Juari na década de 1980.

A participação das esposas jovens fora constante nessas ocupações/ acampamentos. Incentivaram, apoiaram e impeliram os companheiros a ir à luta pela terra. Nos relatos, seus companheiros reconhecem — sorrindo que só estavam na terra por causa delas: "Eu só 'tou com essa terra por causa dela! " (Gilson BARBOSA, 2015, entrevista); "Eu não queria vim mesmo, 
não! Ela que me incentivou" (Marcos MARUJADA, 2015, entrevista). Essa expressão aparece na fala das mulheres também: "Ele veio porque arrastei ele pra aqui!"; "Eu era a primeira querer vim pra cá, ele não queria muito vim, não!"; "Eu falei: 'Se tu não for, eu vou!'”. Declarações tais deixam entrever a coragem e tenacidade dessas mulheres para conseguir um "pedaço de terra".

Questionados sobre as motivações para lutar pela terra, os jovens relataram que era para sair da condição de empregados ou — como nomeiam — de "escravo do leite" - em referência ao trabalho desgastante nas fazendas da região. Mesmo percebendo o trabalho árduo no campo e com as dificuldades de gerar renda no início dos assentamentos — que obrigam a trabalhar fora —, os jovens estão confiantes de que terão condições melhores de vida no campo. Conforme avaliam, na cidade teriam dificuldades para adquirir bens e melhorar o patrimônio, tal qual fizeram seus pais nos assentamentos.

Aspirações permeiam os relatos de vários jovens, homens e mulheres:

Penso assim... as posses, pra que quem quiser começar a vida tem futuro. O meu pai era peão novo quando começou, hoje meu pai vive a vida dele de boa. Tem a renda do leite e tem o gadinho. Não é mais peão de ninguém! É difícil, se o cara não tiver aquela força de vontade... não fica! (Gilson BARBOSA, 2015, entrevista).

Ser assentada é bom demais... a gente tem onde falar: "Aquilo ali é meu! Eu vivo naquilo ali". Dar uma renda boa pra gente. Agora no começo não dá não, né!? Mas futuramente com fé em Deus, vai dar! (SANTOS, Vania., 2015, entrevista).

Trabalhamos tantos anos pros outros e se perguntar assim: "O que você tem, trouxe? Nada! [...] Nós estamos dois anos aqui, já temos nove cabeça de gado, que podemos dizer assim: é nosso! (Juliana REIS, 2015, entrevista).

Eu acho bom mexer com a terra. E também eu vi muitas famílias melhorar de vida né!? Na cidade é assim: você ter um emprego, você conseguir uma casa, já é quase no final da vida. A gente já tem o lugar pra morar. Pode plantar o básico pra sobreviver e ainda pode trabalhar fora pra ter uma renda, até ter estabilidade pra ficar só na dentro terra. Meu pai já tava... meu vô era assentado. Eu vi as pessoas prosperaram aqui no Progresso, saiu mais financiamento (PEREIRA, Luís., 2015, entrevista).

As trajetórias de vida das famílias entrevistadas e as experiências vivenciadas pela juventude nos assentamentos ou na cidade permitiram uma revalorização simbólica da (auto) imagem de camponês. O assentamento rural se associa com local de possibilidades, realização do projeto de vida - seria uma "herança desejada" (CHAMPAGNE, 1986), inclusive entre mulheres, que vêm assegurando a sucessão rural na região do vale do Juari.

O estudo sobre a sucessão no vale diverge do estudo de Bessiére (2010) sobre os arranjos familiares para transmissão da exploração agrícola de viticultores no Sudoeste francês, em que os/as filhos (as) que galgaram posições sociais mais elevadas estão menos propensos a abrir mão da parte de seus direitos. No vale do Juari, filhos (as) que alcançaram uma posição profissional ou econômica relativamente mais estável — seja como funcionário público ou nos assentamentos rurais, por exemplo - estão propensos a abrir mão de parte de seus direitos no lote em favor do irmão ou da irmã apontados à sucessão.

Em meio a gerações descendentes, a disposição de se tornar camponês está balizada nas condições objetivas de reprodução social. Ela alinha a conquista do patrimônio fundiário na produção e geração de renda com a possibilidade de crescimento pessoal e profissional; também pesa nas questões subjetivas transmitidas pelas famílias: a independência no trabalho, a posse da sua terra, o apego à família e o gosto pelo campo.

A conquista da terra e a vida no assentamento se associam à valorização do modo de vida rural, e é vista pelas famílias como consagração da vida, marcada por trajetórias sociais de luta contínua para assegurar, material e simbolicamente, a unidade familiar. Contudo, o estatuto social de "ser camponês" negociado entre as novas gerações passa pela percepção de acesso a direitos, renda, educação e pela conquista de dignidade e cidadania, na compressão do campo como um lugar melhor para viver.

\section{Considerações finais}

As dinâmicas demográficas e os processos sociais com a territorialização dos assentamentos rurais no vale do Juari trouxeram outra perspectiva de rural às novas gerações, que parecem mesmo querer seguir o destino da família e permanecer no campo como projeto de vida. Entretanto, a análise das trajetórias de filhos e netos, filhas e netas permite apreender que a decisão de "ficar" no meio rural não é ato orientado apenas pelos valores apreendidos no campo, mas ainda pelas condições objetivas das famílias de realizar seus 
projetos de vida e alcançar as aspirações de inserção social e econômica.

Todavia, para que possam ter uma decisão mesmo que tácita sobre o futuro herdeiro, as famílias têm desenvolvido arranjos diferentes para dar segurança a todos os membros: investimentos no estudo; apoio financeiro à compra do "direito de lote"; a migração dos jovens como forma de acumular capital econômico para comprar o lote ou pagar por benfeitorias e retornar ao campo; novas ocupações de terras pelos/as jovens com apoio e orientação paterna para garantir a apropriação do patrimônio fundiário - ocupar terras é estratégia de reprodução de que camponeses lançam mão há três gerações.

O cálculo que norteia a decisão das gerações descendentes (homens e mulheres) de permanecer no campo se baseia nas probabilidades objetivas de crescimento profissional, de acesso ao trabalho e de escolarização na cidade. Também se baseia nas possibilidades reais de futuro melhor com a conquista do patrimônio fundiário, a expectativa de geração de renda, o acesso a políticas públicas para o meio rural. Essas condições projetam o modo de camponês como herança não só possível, mas também viável.

A escuta e a leitura dos relatos das famílias e jovens entrevistados (as) não permitem afirmar que as gerações descendentes e vindouras desejam e desejarão permanecer no campo. O que se pode afirmar é que seus membros mais novos revelam ter uma percepção de sua condição de camponês parafraseando Bourdieu e Sayad (1964, p. 102): de certo modo de ser, de certa disposição - "permanente e geral" — para agir ante "o mundo e os outros"; talvez porque tenham permanecido camponeses mesmo sem as condições de sê-lo e de se comportarem como tal. Seu habitus não se dissipou.

\section{Referências Bibliográficas}

BESSIÉRE, Céline. De géneration en géneration: arrangements de famille dans les entreprises viticoles de Cognac. Paris: Raisons d'Agir, 2010.

BOURDIEU, Pierre. Célibat et condition paysanne. Études rurales, $n$. 5/6, p. 32-135, 1962.

BOURDIEU, Pierre. SAYAD, Abdelmalek. Lé déracinement. La crise de l'agriculture traditionnelle en Algérie. Paris: Éditions de Minuit, 1964.
CASTRO, Elisa Guaraná. Entre ficar e sair: uma etnografia da construção social da categoria jovem rural. Rio do Janeiro: Contra Capa, 2013.

CARNEIRO, Maria José; CASTRO, Elisa Guaraná. Juventude rural em perspectiva. Mauad, 2007.

CHAMPAGNE, Patrick. La reproduction de l'identité. Actes de la recherche en sciences sociales, v. 65, p. 41-64, novembre 1986

GARCIA JÚNIOR, Afrânio Raul. O Sul: caminho do roçado: estratégias de reprodução camponesa e transformação social. São Paulo: Marco Zero, 1989.

MOURA, Margarida M. Os deserdados da terra. Rio de Janeiro: Bertrand do Brasil, 1988b.

SILVESTRO, Milton Luiz et al. Os impasses sociais da sucessão hereditária na agricultura familiar. Florianópolis: Epagri; Brasília: Nead/Ministério do Desenvolvimento Agrário, 2001.

STROPASOLAS, Valmir Luiz. O mundo rural no horizonte dos jovens. Florianópolis: ed. UFSC, 2006.

THOMPSON, Edward P. Costumes em comum. Editora Companhia das Letras, 1998.

THOMPSON, Paul. A voz do passado. 3. Rio do Janeiro: Paz e Terra, 2002. 